\title{
Risk Management Analysis of Follow-up Audit in the Construction Stage of Construction Projects
}

\author{
Yongjun Luo \\ Chongqing University, Chongqing 400044, China \\ Email: chinaluoyj@126.com
}

\begin{abstract}
The construction project serves as one of the most important projects in the construction industry. The high cost and the particularity in the implementation generate high risks in the investment and construction process. Over the years, the development of construction project management methods has promoted the management of risk factors. This paper reviews the suggestions of risk management of follow-up audit in construction stage and evaluates its application in construction projects.
\end{abstract}

Keywords: construction project, follow-up audit, construction stage, risk management

\section{Introduction}

The standardized operation of construction projects cannot be separated from the audit supervision of construction projects ${ }^{[1]}$. Follow-up audit is achieved with focuses on management, economy, finance, technology and other aspects ${ }^{[2]}$, which has not only strengthened administrative supervision, but also played a good regulatory role in the use of funds, cost structure and the authenticity, legality and effectiveness of technical measures. In order to improve the asset value of construction projects, the government should adopt effective auditing methods for construction projects.

Follow-up audit of construction projects is more difficult than traditional construction projects. Based on the characteristics of construction projects, it usually takes a long time to build public infrastructure or provide public services ${ }^{[3]}$. In the contract system of construction projects, there are many parties involved, the contract system is relatively complex, and the data transmission of each party is frequently regarded as the weak link in the control process. The content of follow-up audit of construction projects should be deepened with the increase of influencing factors. The concept of asset life cycle management should be introduced to conduct follow-up audit of construction projects and the assets of construction projects should be rationally managed, which is conducive to the successful operation of construction projects. Therefore, this paper proposes to establish an asset management method with tracking audit as the core on the basis of summarizing the concept of asset life cycle management.

In the construction stage of a construction project, attention should be paid to reasonable control of investment and reduction of unnecessary expenditure, so as to achieve the goal of building high-quality assets, meeting functional requirements and reducing later operating costs ${ }^{[4]}$. This paper analyzes how construction projects add value from the perspective of the whole life cycle, and puts forward the method of follow-up audit, including the audit of the construction process and completion process in the construction stage, as well as the necessary contract audit. From the perspective of these three audits, this paper puts forward the implementation path of asset management in the construction stage of construction projects.

\section{Asset risk management in the construction stage with follow-up audit as the core}

Follow-up audit can timely and dynamically audit all materials that constitute final accounts. It is a comprehensive audit, covering all links in the process of project construction ${ }^{[5]}$. The advantage of follow-up audit is that it combines pre-audit and post-audit, so as to avoid excessive focus on defects of a certain stage before or after audit. There are many criteria for the division of audit methods. According to the different audit contents, the follow-up audit can be divided into three categories. In this study, the starting point of this study is the target demand of asset life cycle management, construction project assets as the specific research object and this paper analyzes the starting point and increment mechanism of construction project assets in the construction stage. In the construction stage, the follow-up audit method in the key links is adopted, focusing on the contract audit, construction process audit and completion settlement audit.

The construction stage of a construction project is an important stage in its whole life cycle. In this stage, the special purpose vehicle composed of government and social capital puts the blueprint of the construction project into practice and forms the project asset entity through construction, and provides the foundation for the operation stage. Asset life cycle management is the enrichment and development of the concept of life cycle cost management ${ }^{[6]}$. In the ISO55000 asset 
management system, if the project-related management system is integrated with the concept of asset life cycle management, the construction project can reduce a large part of the cost under the premise of meeting the same performance and requirements ${ }^{[7]}$. Asset life cycle management is a comprehensive and dynamic process ${ }^{[8]}$. From the point of view of the whole life cycle, construction projects have gone through the process of asset planning, asset formation, asset dissipation and asset replenishment. Therefore, it is more appropriate and feasible to consider construction projects as "assets". By recording and tracking assets, the generated data can provide decision support for the related activities of the project ${ }^{[9]}$. The asset life cycle management-construction project model combines the work contents of different stages of the construction project with the whole life cycle of the asset, so as to achieve the optimal comprehensive goal in all aspects of the asset use. In the construction stage, the uncertainty of the construction project leads to more complex risk factors

\section{Key contents of risk management in construction project follow-up audit}

The PMBOK make it clear of the risk management participants as: the project manager, selected project team members, anyone in the organization responsible for managing risk planning and execution activities, and others as needed ${ }^{[10]}$. The result of the work at this stage should be a risk management plan, including: approach, roles, responsibilities, budget, timing, and risk categories. To thoroughly review documentation at the organizational and program levels, and then develop a risk management strategy for the project. The main purpose of developing this policy is to show how risk management can be integrated into project management activities. A risk management strategy includes the following elements: a brief introduction, risk management procedures, tools and techniques, required records, reports, deadlines for risk management activities, roles, responsibilities, rating scale, risk category, risk response category, early indicator warning, risk tolerance, and risk budgeting.

The contract management, project change, claim management and completion settlement of the construction project can be regarded as the key content of the construction stage of the project. Timely follow-up auditing for this content is helpful to reduce the cost of engineering construction in the process of unreasonable and unnecessary spending, so the the construction cost of the project can be reduced without function changes, which is a value-added approach to reduce costs, or to add the value of asset of construction project and sustainability and to add cash influx and operation revenue of construction project in operation and maintenance stage, which is a value-added approach. In the process of construction, project units constantly optimize work, reduce costs and increase benefits, so that social capital can obtain good benefits in the operation stage.

\subsection{Contract risk management for follow-up audit in construction projects}

As the construction project is started, the relevant contract has been basically determined. Construction project contract management is not to reduce the function of the project, but to track audit in the contract to clarify the requirements of time limit, quality and cost, to maximize the realization of the objectives of all parties. During the performance of the contract, if relevant conditions permit, social capital can reasonably optimize the work in the construction process of the construction project, because the special purpose company is likely to be the operator after the completion of the project construction. Optimizing work tasks is not only conducive to increasing the trust and recognition of the government's social capital, but also conducive to providing public services in the later stage. This process not only promotes social capital, but also improves public satisfaction with public services.

Time limits for project control. If there is no technology inheritance between different processes, the project unit can reasonably choose the process for construction according to the requirements of the project. Quality control. The construction subject of a construction project usually provides services for the public and takes a long time for operation and maintenance. The continuous optimization of construction process will also affect the performance of operation and maintenance in the later stage of construction project. The project unit should fully integrate the asset life cycle management concept into the quality control of the construction project and solve the problems encountered in the construction process. In addition, the SPV shall ensure the performance of the contract. The government and other parties should also fulfill their obligations in a timely manner so that the project can proceed on schedule. Therefore, follow-up audit institutions should audit the contract management process of all parties in the construction process of government and social capital as well as the key audit points in the contract management process during the construction stage.

\subsection{Asset risk management of follow-up audit during construction}

Asset virtualization is a problem that is likely to arise during construction, which makes the price formed by the construction unit in the market far higher than its actual value, thus affecting the efficiency of public services. In the process of construction, the quantity of main construction project and the construction of concealed project are conducted with follow-up audit in construction. 
The audit agency should focus on checking the authenticity and accuracy of the quantities, whether there is deviation from the quantities in the construction drawings, whether the deviation range is reasonable, so as to avoid errors and omissions in the list as far as possible. When there is a serious deviation between the quantities and the original data, the reasons for this situation shall be rechecked. In case of design change and other phenomena, the reasons for the change should be rechecked to determine whether it is for design optimization or change without charge, and the audit results should be compiled into a report to accumulate experience for the next construction. Checking concealed works, the construction of concealed work plays a vital role in the quality of the project. The concealed works are finally covered. Timely auditing the process and results of the covert works is an important step to ensure the step-by-step completion, program compliance and data integrity of the covert works.

\subsection{Asset risk management for follow-up audit during completion acceptance}

The audit of completion settlement is an effective way to check the effect of cost control. The Completion Settlement Report contains the data related to the construction of the project and reflects the total cost of the construction of the project. Through tracking the authenticity and integrity of audit data, audit institutions can check whether social capital has taken reasonable and effective measures to control the construction cost of the project, and whether the corresponding cost-saving effect has been achieved in the construction process. In the process of follow-up audit, it is also necessary to audit whether the social capital has taken certain measures in the construction process of the construction project, so as to pave the way for the improvement of the efficiency of the construction project, the reduction of operating costs, the improvement of operating income and the increase of cash flow inflow.

Acceptance shall be carried out in accordance with the procedures. After the completion of the construction project, the relevant departments shall organize the acceptance of the project. The acceptance shall be made in accordance with the provisions of the contract, which should in strict conformance with the provisions of the contract, and meet the corresponding acceptance standards. If it does not meet the acceptance standards, the project unit shall take corresponding repair measures. Whether the concealed acceptance record of construction project is complete. In the early stage of the construction project, the special purpose company shall formulate a detailed acceptance plan for concealed works and determine the acceptance quantity and relevant data of concealed works, which is conducive to the smooth construction of the project.

The follow-up audit institution shall examine whether the acceptance of concealed works conforms to the corresponding standards, whether there are relevant data records of self-inspection in advance, and whether the acceptance of concealed works is carried out in accordance with the relevant time limit. It is strictly prohibited to make up for acceptance afterwards. Whether the records in the hidden acceptance report are detailed and complete to avoid the phenomenon that the data records are too general. Reviewing relevant acceptance and certificate. First of all, we must strictly examine whether the relevant procedures are reasonable and lawful. Secondly, we should conduct a detailed investigation on the causes of these changes, and investigate whether these changes have achieved the purpose of improving the operation efficiency of construction projects, making the results of construction projects conducive to the realization of public services, and providing empirical data for the next project construction. Check whether the quantity and price are in line with the agreement between government and private capital. According to the existing relevant information, check whether there is a large deviation between the quantities and the original agreement, and whether the calculation of various costs is reasonable. Wrong audits during calculation should be checked. After the review of the relevant technical data, the relevant calculation data in the completion settlement report shall also be strictly reviewed.

\section{Conclusion}

The construction stage of a construction project is the basis of realizing the blueprint in the design stage, providing physical assets for the operation stage. It is an indispensable link in the whole life cycle of a construction project. Therefore, some measures must be taken to ensure the success of construction projects. For example, to pay attention to contract management, completion settlement follow-up audit of construction process and construction stage, the interest-oriented asset management can be transformed into value-oriented asset management, which ensures the reasonable interests of the project parties and the maximization of public interests.

\section{References}

[1] Ge Bocheng. Discussion on the problems and countermeasures of follow-up audit of infrastructure project[J]. Economist. 2021; (06): 103-104. 
[2] Chen Xiangning. The importance of the whole process follow-up audit of engineering project[J]. Green Environment Protection Building Materials. 2021; (05): 125-126.

[3] Lu Min. Research on the implementation of whole-process construction cost follow-up audit [J]. Creat Living. 2021; (05): 136-137.

[4] Zhuang You, He Huaqing, Que Qinghua, Huang Tongquan, Han Qing. Analysis on key points of project follow-up audit and application of results[J]. Yunnan Water Power. 2021; 37(05): 164-166.

[5] Li Wanquan, Wang Xiaojuan. Research on whole-process follow-up audit of construction cost [J]. Construction And Budget. 2021; (04): 14-16.

[6] Cheng Xing. Research on the whole-process follow-up audit control of construction cost [J]. Building Technology. 2021; (06): 98-100.

[7] Zheng Hanxiao, Xu Qingyang. Research on the related issues of follow-up audit of construction project in China[J]. Market Weekly. 2021; 34(03): 107-110.

[8] Zhu Jingjing.Analysis of follow-up audit of infrastructure project[J]. Marketing Circle. 2021; (08): 98-99.

[9] Peng Yuhong, Ni Wei. Research on the cutting point of construction project follow-up audit [J]. Jiangxi Building Materials. 2021; (01): 218-219.

[10] Qian Tao. Research on optimization of project follow-up audit from the perspective of risk-oriented audit[J]. Accounting Learning. 2020; (34): 137-138. 